\title{
Associations between walking speed and participation, according to walking status in individuals with chronic stroke
}

\author{
Iza Faria-Fortini ${ }^{\mathrm{a}, *}$, Janaine C. Polese ${ }^{\mathrm{b}}$, Christina D.C.M. Faria ${ }^{\mathrm{c}}$ and Luci F. Teixeira-Salmela ${ }^{\mathrm{c}}$ \\ ${ }^{a}$ Department of Occupational Therapy, Universidade Federal de Minas Gerais, Belo Horizonte, Brazil \\ ${ }^{\mathrm{b}}$ Department of Physical Therapy, Faculdade de Ciências Médicas de Minas Gerais, Belo Horizonte, Brazil \\ ${ }^{\mathrm{c}}$ Department of Physical Therapy, Universidade Federal de Minas Gerais, Belo Horizonte, Brazil
}

\begin{abstract}
.
BACKGROUND: Reduced walking speed (WS) may lead to restrictions in participation of individuals with stroke, however, the relationships between WS and participation still need to better clarified.

OBJECTIVE: To evaluate the relationships between WS and participation and compare the levels of participation of individuals with chronic stroke, who were stratified according to their walking status.

METHODS: One-hundred and five individuals with stroke ( $58 \pm 12$ years; 61 men) participated. WS was measured by the 10-meter walking test and reported in $\mathrm{m} / \mathrm{s}$. The participants were stratified into three walking status groups: household (WS $<0.4 \mathrm{~m} / \mathrm{s})$, limited-community $(0.4 \mathrm{~m} / \mathrm{s}-0.8 \mathrm{~m} / \mathrm{s})$, and full-community ambulation $(>0.8 \mathrm{~m} / \mathrm{s})$. Participation was assessed by the Brazilian version of the Assessment of Life Habits 3.1 (LIFE-H 3.1-Brazil).

RESULTS: Between-group analyses revealed statistically significant differences between the household, limited-community, and full-community ambulators regarding the LIFE-H 3.1 total $(\mathrm{F}=17.5 ; p<0.0001)$, as well the daily activity $(\mathrm{F}=12.3$; $p<0.0001)$ and social role $(\mathrm{F}=19.0 ; p<0.0001)$ domain scores. Measures of WS were correlated with the daily activity $(r=0.50, p<0.0001)$, social role $(r=0.53, p<0.0001)$, total LIFE-H scores $(r=0.53, p<0.0001)$, and most of the LIFE-H categories $(r=0.23-0.56)$.

CONCLUSIONS: WS was significantly correlated with participation and was able to distinguish between individuals with stroke, who had different levels of participation.
\end{abstract}

Keywords: Walking speed, social participation, stroke

\section{Introduction}

Stroke is one of the leading causes of long-term disability worldwide (Katan \& Luft, 2018). After a stroke, impairments, such as spasticity, muscle weakness, impaired selective motor control, proprioceptive deficits, fear of falling, and cardiorespiratory

*Address for correspondence: Professor Iza de Faria-Fortini, Ph.D., Department of Occupational Therapy, Universidade Federal de Minas Gerais, Avenida Antônio Carlos, 6627, Campus Pampulha, 31270-901 Belo Horizonte, MG, Brazil. Tel.: +55 313409 4795; E-mail: izafaria@yahoo.com.br. deficits may limit walking ability (Balaban \& Tok, 2014; Wing, Lynskey, \& Bosch, 2012). These impairments lead to asymmetrical walking patterns, increases in energy expenditure, and decreases in walking speed (Wing, Lynskey, \& Bosch, 2012). Walking speed has been shown to be a strong predictor of future vascular events (Kawajiri et al., 2019) and community-walking status (Rosa, Marques, Demain, \& Metcalf, 2015) of individuals with stroke. In addition, walking speed has been used as a powerful outcome in randomized clinical trials (Barclay, Stevenson, Poluha, Ripat, Nett, \& Srikesavan, 
2015; Mehrholz, Thomas, \& Elsner, 2017), longitudinal studies (Aaslund et al., 2017; Rosa, Marques, Demain, \& Metcalf, 2015), has also been described as a functional vital sign or indicator of overall health and functional levels (Middleton, Fritz, \& Lusardi, 2015; Lusardi, 2012).

Walking speed was previously categorized to define functional walking status after a stroke. Perry, Garrett, Gronley, and Mulroy (1995) used the following three cut-off values to determine functional ambulation categories of individuals with stroke, based upon their walking speeds: household ambulation (speeds $<0.4 \mathrm{~m} / \mathrm{s}$ ), which correspond to severe gait limitations; limited-community ambulation (speeds between 0.4 and $0.8 \mathrm{~m} / \mathrm{s}$ ), which indicate moderate gait limitations; and communityambulation (speeds $>0.8 \mathrm{~m} / \mathrm{s}$ ), which reflect mild walking limitations.

Increases in walking speed that result in a transition to a higher functional walking status have shown to results in higher levels of participation (Schmid et al., 2007). Participation is defined by the International Classification of Functioning, Disability and Health (ICF) as the 'individual's involvement in life situations' (WHO, 2001). Based upon the conceptual model of the Disability Creation Process, participation is operationalized through the concept of life habits, which are defined as 'daily activities and social roles, which ensure the survival and development of an individual in society throughout life' (Noreau, Fougeyrollas, \& Vicent, 2002).

Restrictions in participation are consequences of chronic conditions, such as stroke (Faria-Fortini et al., 2017; Vicent-Onabajo \& Blasu, 2016). Good ability of locomotion is required to carry-out activities in the home and community environments, which is crucial for performing daily activities and social roles (Faria-Fortini, Basílio, Scianni, Faria, \& TeixeiraSalmela, 2018). Recovery of participation is the main priority for patients and rehabilitation professionals (Obembe \& Eng, 2016), since participation is positively related to better perception of quality of life (Vicent-Onabajo, Hamzat, \& Owalabi, 2015), as well as health and well-being (Law, 2002).

Reduced walking speed may lead to restrictions in participation of individuals with stroke (FariaFortini, Basílio, Scianni, Faria, \& Teixeira-Salmela, 2018; Faria-Fortini et al., 2017; Schmid et al., 2007). However, the relationships between walking speed and participation still need to be better clarified. For instance, the relationships between walking speed and different categories of participation, including activities carried-out in the home and community environments, have not been sufficiently analyzed. Furthermore, the analysis of the different domains of participation, considering the functional categories of ambulation, was not previously performed.

Therefore, the aims of the present study were to evaluate the relationships between walking speed and participation; and to compare the levels of participation of individuals with chronic stroke, who were stratified into three walking status groups (household, limited- community, and full-community ambulation). It was hypothesized that there would be significant relationships between participation and walking speed and that individuals with higher walking status would have higher levels of participation.

\section{Methods}

\subsection{Study population and procedures}

For this exploratory study, the participants were recruited on a volunteer basis from the general community of the city of Belo Horizonte, Brazil, from lists of previous research projects and by means of advertisements and by screening out-patient clinics in public rehabilitation services, between March, 2013 and August, 2014. All participants were screened to ensure that they had: clinical diagnosis of a primary or recurring unilateral stroke; a time since the onset of the stroke of at least six months; $\geq 20$ years of age; ability to walk 10 meters with or without an assistive devices; and hemiparesis, as determined by weakness of handgrip or knee extensor muscles and/or increased tonus of the elbow flexor and knee extensor muscles (Faria-Fortini, Basílio, Scianni, Faria, \& Teixeira-Salmela, 2018). Those, who had other clinical conditions not related to stroke, were not able to communicate, and had cognitive impairments, which were screened using the following education-adjusted cut-off scores on the Mini-mental State Examination: 13 for the individuals with illiteracy, 18 for those with elementary and middle education, and 26 for those with high education (Bertolucci, Brucki, Campacci, \& Juliano, 1994), were excluded.

The participants were informed about the objectives of the study and were invited to provide consent, based upon previous approval from the Institutional ethical review board (\#066093312.0.0000.5149). Trained personnel who had at least five years of clinical and/or research experience in the area of stroke 
rehabilitation collected the data within a research laboratory setting on one day (2.5-hour sessions).

Initially, for characterization purposes, the participants underwent a physical examination and an interview for the collection of the following data: age, sex, paretic side, time since the onset of the stroke, and motor recovery, which was evaluated by the Fugl-Meyer scale (FM) scores (Sullivan et al., 2011).

\subsection{Outcome measures}

Walking speed was measured by the 10 -meter walking test and reported in $\mathrm{m} / \mathrm{s}$. Participants were instructed to walk along a 14-meter course at their comfortable speeds, wearing their habitual shoes, orthoses, and assistive devices (Faria, TeixeiraSalmela, Gomes Neto, \& Rodrigues-de-Paula, 2012). They received the following standardized verbal command: "walk at your normal and comfortable pace" (Nascimento, Caetano, Freitas, Morais, Polese, $\&$ Teixeira-Salmela, 2012). The time to cover the central 10 meters was recorded and the speed $(\mathrm{m} / \mathrm{s})$ was calculated. Only one trial has shown to provide consistent and reliable results (Faria, Teixeira-Salmela, Gomes Neto, \& Rodrigues-dePaula, 2012). Based upon their walking speed values, the participants were stratified into three walking status groups, as follows: household ambulation (speeds $<0.4 \mathrm{~m} / \mathrm{s}$ ), limited-community ambulation (speeds between $0.4 \mathrm{~m} / \mathrm{s}$ and $0.8 \mathrm{~m} / \mathrm{s}$ ), and full-community ambulation (speeds $>0.8 \mathrm{~m} / \mathrm{s}$ ) (Perry, Garrett, Gronley, \& Mulroy, 1995).

Participation was assessed by the Brazilian version of the Assessment of Life Habits 3.1 (LIFE-H 3.1-Brazil), which demonstrated satisfactory measurement properties with individuals with stroke (Assumpção, Faria-Fortini, Magalhães, Basílio, Carvalho, \& Teixeira-Salmela, 2015). The LIFE-H 3.1 includes 77 questions regarding 12 categories of life habits, which are divided into two domains: daily activities (nutrition, fitness, personal care, communication, housing, and mobility) and social roles (responsibilities, interpersonal relationships, community life, education, employment, and recreation). In the present study, the 'education' category was not included in the analysis, since it contemplates life habits which are not commonly carried-out, leaving 11 categories (Faria-Fortini et al., 2017). All questions are scored, based upon the combination of the level of accomplishment and the type of the required assistance (technical assistance, physical arrangements, and human help), which creates weighted single scores, ranging from to zero (total restriction in participation, meaning that the life habits are not accomplished) to nine (maximal level of participation, meaning that the life habits are performed without difficulty and help) (Assumpção, Faria-Fortini, Basílio, Magalhães, Carvalho, \& Teixeira-Salmela, 2016; Noreau, Fougeyrollas, \& Vicent, 2002). The summation of the raw scores was transformed on a $0-10$ scale (normalized scores), considering the number of the items by the categories and the possibility of the occurrence of non-applicable items, using the following formula: Normalized score $=[\Sigma$ (Raw scores) $* 10]$ $\div$ [(Number of applicable items)*9] (Assumpção, Faria-Fortini, Basílio, Magalhães, Carvalho, \& Teixeira-Salmela, 2016; Noreau, Fougeyrollas, \& Vicent, 2002). Higher scores indicate higher levels of participation (Assumpção, Faria-Fortini, Basílio, Magalhães, Carvalho, \& Teixeira-Salmela, 2016; Noreau, Fougeyrollas, \& Vicent, 2002).

For the analyses, the scores on the daily activity and social role domains were registered, considering that they assess different dimensions of the participation construct (Assumpção, Faria-Fortini, Magalhães, Basílio, Carvalho, \& Teixeira-Salmela, 2015).

\subsection{Statistical analysis}

The sample size of at least 19 individuals per group (57 individuals in total) was estimated, considering a power of $80 \%$, an $\alpha$ of 0.05 , and an effect size of 0.35 (Vanbrabant, Van De Schoot, \& Rosseel, 2015).

Descriptive statistics, tests for normality (Kolmogorov-Smirnov), and equality of variance (Levene) were calculated for all outcomes. Differences between the groups (household, limitedcommunity, and full-community ambulators) were investigated using one-way analysis of variance (ANOVA), followed by the Tukey HSD post-hoc tests (Khanittanuphong \& Tipchatyotin, 2017).

Pearson's correlation coefficients $(r)$ were calculated to examine the relationships (magnitude, direction, and significance) between measures of walking speed and the LIFE-H 3.1 scores (total, daily activities, and social roles) and LIFE-H 3.1 categories (daily activities: nutrition, fitness, personal care, communication, housing, and mobility; and social roles: responsibilities, interpersonal relationships, community life, employment, and recreation). The strength of the relationships was based upon 
Table 1

Characteristics of the participants (household, limited-community, and full-community ambulators)

\begin{tabular}{lcccc}
\hline Characteristic & $\begin{array}{c}\text { All } \\
\text { participants } \\
(n=105)\end{array}$ & $\begin{array}{c}\text { Household } \\
(n=17)\end{array}$ & $\begin{array}{c}\text { Limited } \\
\text { community } \\
(n=31)\end{array}$ & $\begin{array}{c}\text { Full } \\
\text { community } \\
(n=57)\end{array}$ \\
\hline $\begin{array}{l}\text { Age (years), mean (SD) } \\
\text { Sex (men), n (\%) }\end{array}$ & $58(12)$ & $64(10)$ & $59(10)$ & $56(12)$ \\
$\begin{array}{l}\text { Time since the onset of the stroke } \\
\quad \text { years), mean (SD) }\end{array}$ & $51(58)$ & $8(47)$ & $19(61)$ & $34(60)$ \\
$\begin{array}{l}\text { Cognition (MMSE scores 0-30), } \\
\text { mean (SD) }\end{array}$ & $25(3)$ & $24.3(4.8)$ & $5.3(4.6)$ & $6.0(5.9)$ \\
$\begin{array}{l}\text { Motor impairment (FMA scores: } \\
\quad 0-100), \mathrm{n}(\mathrm{SD})\end{array}$ & $71(23)$ & $59(25)$ & $25(3)$ & $25(3)$ \\
Walking speed (m/s) & $0.83(0.33)$ & $0.30(0.13)$ & $0.68(0.10)$ & $1.06(0.20)$ \\
\hline
\end{tabular}

SD: standard deviation; MMSE: Mini-mental State Examination; FMA: Fugl-Meyer Assessment.

Table 2

Mean (SD) total LIFE-H scores and daily activity and social role domain scores and comparisons between the groups (household, limited community, and full-community ambulators)

\begin{tabular}{lccccc}
\hline $\begin{array}{l}\text { LIFE-H } \\
\text { domains }\end{array}$ & $\begin{array}{c}\text { All } \\
\text { participants } \\
(n=105)\end{array}$ & $\begin{array}{c}\text { Household } \\
\text { ambulators } \\
(n=17)\end{array}$ & $\begin{array}{c}\text { Limited } \\
\text { community } \\
\text { ambulators } \\
(n=31)\end{array}$ & $\begin{array}{c}\text { Community } \\
\text { ambulators } \\
(n=57)\end{array}$ & F; $p$ values \\
\hline Daily activity & $7.5(1.4)$ & $6.4(1.6)^{\mathrm{a}}$ & $7.2(1.2)^{\mathrm{b}}$ & $8.0(1.1)^{\mathrm{c}}$ & $12.3 ;<0.0001$ \\
Social role & $6.9(2.1)$ & $4.7(1.8)^{\mathrm{a}}$ & $6.5(1.7)^{\mathrm{b}}$ & $7.7(1.9)^{\mathrm{c}}$ & $19.0 ;<0.0001$ \\
Total & $7.2(1.6)$ & $5.6(1.6)^{\mathrm{a}}$ & $6.9(1.4)^{\mathrm{b}}$ & $7.9(1.4)^{\mathrm{c}}$ & $17.5 ;<0.0001$ \\
\hline
\end{tabular}

Different letters indicated statistically significant differences.

the following Munro's correlation descriptors: very low (0-0.25), low (0.26-0.49), moderate (0.50-0.69), high (0.70-0.89), and very high (0.90-1.00) (Munro, 2005). All analyses were performed with the SPSS Software (version 16.0) with a significance level of $5 \%$.

\section{Results}

\subsection{Participants' characteristics}

Individuals with stroke $(n=485)$ were screened by telephone and 152 agreed to participate and were scheduled for the assessments. However, 30 did not show up on the day of the test, despite prior confirmation. Thus, 122 individuals were screened, but 17 were excluded for the following reasons: cognitive impairments $(n=6)$, other non-stroke related conditions $(n=5)$, inability to walk with or without assistive devices $(n=4)$, and bilateral stroke $(n=2)$. Therefore, 105 participants, 61 men, who had a mean age of 58 years (SD 12) and a mean time since the onset of the stroke of 5.5 (SD 5.3) years, were evaluated. Of the 105 participants, 17 (16\%) were household, 31 (30\%) were limited-community, and 57 (54\%) were full-community ambulators. Table 1 summarizes the characteristics of the participants, according to their walking status. As given in Table 1, the groups were similar regarding the time since the onset of the stroke $(p=0.52)$, and cognition $(p=0.72)$. However, statistically significant differences were found for age $(p=0.03)$ and motor recovery $(p=0.009)$. Individuals who were household ambulators were older when, compared to the limited community and full-community ambulators and those, who were full-community ambulators, had less impairment in motor function, when compared to the limited community and household ambulators.

\subsection{Comparisons between the groups}

ANOVA revealed statistically significant differences between the household, limited-community, and full-community ambulators regarding the LIFE-H 3.1 total $(\mathrm{F}=17.5 ; p<0.0001)$, daily activity $(\mathrm{F}=12.3 ; p<0.0001)$, and social role $(\mathrm{F}=19.0$; $p<0.0001$ ) domain scores (Table 2). These results indicated that individuals, who had full-community 
Table 3

Mean (SD) scores of both LIFE-H domains and Pearson correlation coefficients between walking speed and LIFE-H domain scores

\begin{tabular}{lcc}
\hline LIFE-H domain & Mean (SD) & $r ; p$ values \\
\hline Daily activity & & \\
$\quad$ Nutrition & $7.4(1.9)$ & $0.38^{* * *}$ \\
Fitness & $8.1(1.8)$ & $0.30^{*}$ \\
Personal care & $8.2(1.6)$ & $0.34^{* * *}$ \\
Communication & $8.1(1.5)$ & $0.23^{*}$ \\
Housing & $6.9(1.8)$ & $0.44^{* * *}$ \\
Mobility & $5.8(2.4)$ & $0.56^{* * *}$ \\
Social role & & \\
$\quad$ Responsibilities & $7.7(2.1)$ & $0.40^{* * *}$ \\
Interpersonal relationships & $8.9(1.7)$ & $0.17^{\mathrm{NS}}$ \\
Community life & $6.8(2.9)$ & $0.56^{* * *}$ \\
Employment & $6.5(3.5)$ & $0.27^{*}$ \\
Recreation & $4.8(2.8)$ & $0.43^{* * *}$ \\
\hline SD $=$ standard deviation; NS $=$ not & significant; ${ }^{* * *} p<0.0001 ;$ \\
${ }^{* *} p<0.001 ;{ }^{*} p<0.05$. & &
\end{tabular}

ambulation status, reported higher levels of participation, independent of the LIFE-H domain.

\subsection{Associations between the variables}

Statistically significant and positive correlations of moderate magnitudes were found between walking speed measures and the LIFE-H daily activity domain scores $(r=0.50, p<0.0001)$, social role domain scores $(r=0.53, p<0.0001)$, and total LIFE-H scores $(r=0.53, p<0.0001)$.

Within the daily activity domain, low-to-moderate relationships $(r=0.30-0.56)$ were found between walking speed and all categories, except the communication category, which showed very low correlation $(r=0.23)$.

Within the social role domain, low-to-moderate relationships $(r=0.27-0.56)$ were found between walking speed and all categories, except between the interpersonal relationship category, which was not statistically significant $(p=0.08)$.

\section{Discussion}

This study aimed at evaluating the relationships between walking speed and participation domains and comparing the levels of participation of individuals with chronic stroke, who had different walking status, i.e., household, limited-community, and fullcommunity ambulators. Significant associations were found between walking speed and both assessed participation domains, as well as the majority of the domain categories. Our hypothesis was con- firmed, since the results indicated that individuals who walked faster, reported higher levels of participation.

Walking speed was able to distinguish between individuals, who had different levels of participation. Compared to the household and limited-community ambulator groups, the individuals, who had fullcommunity ambulation status reported higher total LIFE-H scores and both daily activity and social role domain scores. Individuals, who walked at speeds above $0.8 \mathrm{~m} / \mathrm{s}$ reported higher levels of social participation (Faria-Fortini et al., 2017). Previous studies reported similar results, since increases in walking speed were found to be associated with better perception of quality of life, assessed by the Stroke Impact Scale (SIS) (Khanittanuphong \& Tipchatatyotin, 2017; Schmid et al., 2007). When analyzing the SIS participation domain, walking speed explained $32 \%(p<0.01)$ of the variance in perceived participation (Flansbjer, Downham, \& Lexell, 2006). In addition, compared to several impairment-based measures, walking speed showed to be the best predictor $\left(\mathrm{R}^{2}=39 \% ; p<0.0001\right)$ of participation after stroke, evaluated by the LIFE-H (Faria-Fortini, Basílio, Scianni, Faria, \& Teixeira-Salmela, 2018).

Walking speed was positively correlated with the LIFE-H total scores, daily activity and social role domains. The mobility category of the daily activity sub-scale and the community life category of the social role sub-scale were moderately correlated with walking speed. These categories include life habits that require the individual's ability to get around on streets and sidewalks, as well as get to public buildings and commercial establishments in the community (Assumpção, Faria-Fortini, Basílio, Magalhães, Carvalho, \& Teixeira-Salmela, 2016; Noreau, Fougeyrollas, \& Vicent, 2002). Walking ability is important for community integration (van de Port, Kwakkel and Linderman, 2008). Community ambulation requires managing environmental demands, such as the ability to avoid obstacles and safely cross streets (Timmermans, Roerdink, van Ooijen, Meskers, Janssen, \& Beek, 2016). Previous study reported that a walking speed of at least $1.2 \mathrm{~m} / \mathrm{s}$ is required to safely cross the streets in São Paulo, Brazil (Duim, Lebrão, \& Antunes, 2017). Thus, individuals, who walk slower, may feel insecure and restrict their activities within the community environment.

Within the daily activity domain, the categories related to nutrition, fitness, personal care, and housing, as well as those related to responsibilities and recreation within the social role domain, correlations 
of low magnitudes were observed. The categories contemplated within the daily activity domain involve life habits commonly carried-out in the home environment, such as preparing meals, getting in and out of bed, using the bathroom and toilet, and doing household tasks (Assumpção, Faria-Fortini, Basílio, Magalhães, Carvalho, \& Teixeira-Salmela, 2016; Noreau, Fougeyrollas, \& Vicent, 2002). It should be noted that the participants of the present study were at the chronic post-stroke stages. Thus, they possibly had adopted compensatory strategies, such as changes in the environment and/or modifications of the task, to better accomplish their life habits (Donnellan, Hevey, Hickey, \& O'Neill, 2012). Additionally, within the social role domain, the categories related to responsibilities and recreation include life habits with similar characteristics. They predominantly require cognitive and emotional skills for their accomplishment, such as recognizing the value of money, using bank cards, and participating in artistic, cultural, or craft activities. Thus, it is possible that higher walking speeds would not be crucial to perform these activities, considering the multifactorial nature of participation.

Finally, a correlation of very low magnitude was observed between the communication category and walking speed. This category considers life habits that primarily involve upper-limb function, such as writing, using a computer, and functions of language, such as communicating with another person or a group of people at home or in the community or using a phone (Assumpção, Faria-Fortini, Basílio, Magalhães, Carvalho, \& Teixeira-Salmela, 2016; Noreau, Fougeyrollas, \& Vicent, 2002). There was not found any correlation between walking speed and the interpersonal relationship category. Interpersonal relationships may be related to other aspects of functionality, such as depressive symptoms (Rozon $\&$ Rochette, 2015). A previous study showed significant associations between the presence of depressive symptoms and interpersonal relationships at first month after the stroke and reduced participation at 6 months (Rozon \& Rochette, 2015). Individuals, who had depressive symptoms shortly after a mild stroke, were nearly 3.5 times less likely to have optimal level of participation at 6 months regarding interpersonal relationships $(p=0.003)$ (Rozon \& Rochette, 2015).

Other personal or functional factors may interfere with participation of individuals with chronic conditions, such as stroke. Post-stroke functional disabilities and physiological changes associated with aging should be concomitantly analyzed. In this study, older individuals had househould ambulation, whereas no difference was observed in relation to age in the group of individuals, who were limitedcommunity and full-community ambulators. In addition, individuals who had full-community ambulation status had fewer motor-function impairments, compared to those who were limited-community and household ambulators. Declines in usual walking speed are often associated with aging (Bohannon \& Andrews, 2011), probably as a result of physiological changes, which include motor control, balance, postural reflexes, sensory and sensorimotor integration and cardiopulmonary functions (Pirker $\&$ Katzenschlager, 2017). However, for individuals who have chronic conditions, such as stroke, it is important to consider the concomitant influence of residual impairments, such as motor function, muscle strength, coordination, and balance that can interfere with locomotion ability (Flansbjer, Downham, \& Lexell, 2006; Patterson et al., 2007; Robinson, Shumway-Cook, Matsuda, \& Ciol, 2011) and, consequently, social participation (Faria-Fortini, Basílio, Scianni, Faria, \& Teixeira-Salmela, 2018). In this sense, reduced walking speed may be associated with non-modifiable factors, such as age, but especially with modifiable factors, such as motor impairments.

Social participation is a key outcome for rehabilitation (Obembe \& Eng, 2016). In turn, mobility is an important skill for independence and regain mobility is the main priority of individuals with stroke and rehabilitation professionals. The ability to walk, for instance, is the main goal for most individuals during rehabilitation (Dobkin, 2005). Participation is a complex construct that involves the accomplishment of life habits in different contexts and require, in a greater or lesser extent, different components of functioning. Despite the complexity of the participation construct, walking speed was significantly correlated with most categories of the LIFE-H domains and was able to differentiate between levels of participation, according to the ambulation status. In this sense, walking speed appears to be an important measure to be obtained, when participation of post-stroke individuals is considered. However, due to the wide nature of the participation construct, the assessment should not be restricted to this component of functionality. It is important to point-out that walking speed can be quickly and accurately assessed within most clinical and research settings and, recently, was recognized as the functional sixth vital sign, due to its relation to other functional measures (Lusardi, 2012). 
The strength of the present study is that it included a larger sample, who had different levels of disability. However, this study is not without limitations. First, due to the design nature of the study, causal relationships cannot be determined. Second, the fact that the sample size was not uniformly distributed between the groups, may have influenced the results. Third, only individuals at the chronic stages of stroke, who had the ability to walk independently, were included. Thus, the present findings cannot be generalized to others, who had different characteristics.

\section{Conflict of interest}

All authors declare that they have no conflicts of interest.

\section{Funding}

Financial support provided by the Pró-Reitoria de Pesquisa da Universidade Federal de Minas Gerais (PRPq/UFMG).

This research was supported by the Brazilian Funding Agencies: CAPES (code \#001), CNPq (\#304430/2014-0), and FAPEMIG (PPM-00082-16).

\section{References}

Aaslund, M. K., Moe-Nilssen, R., Gjelsvik, B. B., Bogen, B., Næss, H., Hofstad, H., et al. (2017). A longitudinal study investigating how stroke severity, disability, and physical function the first week post-stroke are associated with walking speed six months post-stroke. Physiotherapy Theory and Practice, 33, 932-942.

Assumpção, F. S. N., Faria-Fortini, I., Basílio, M. L., Magalhães, L. C., Carvalho, A. C., \& Teixeira-Salmela, L. F. (2016). Cross-cultural adaptation of LIFE-H 3.1: An instrument for assessing social participation. Cadernos de Saúde Pública, 32, e00061015 [article in Portuguese].

Assumpção, F. S. N., Faria-Fortini, I., Magalhães, L. C., Basílio, M. L., Carvalho, A. C., \& Teixeira-Salmela, L. F. (2015). Measurement properties of the LIFE-H 3.1-Brasil for the assessment of social participation after stroke. Revista de Neurociências, 23, 506-515. [article in Portuguese].

Balaban, B., \& Tok, F. (2014). Gait disturbances in patients with stroke. $P M \& R, 6,635-642$.

Barclay, R. E., Stevenson, T. J., Poluha, W., Ripat, J., Nett, C., \& Srikesavan, C. S. (2015). Interventions for improving community ambulation in individuals with stroke. Cochrane Database of Systematic Reviews, 3, CD010200. doi: 10.1002/14651858.CD010200

Bertolucci, P. H. F., Brucki, S. M. D., Campacci, S. R., \& Juliano, Y. (1994). The Mini-Mental State Examination in an outpatient population: Influence of literacy. Arquivos de NeuroPsiquiatria, 52, 1-7. [article in Portuguese].

Bohannon, R. W., \& Williamns, A. A. (2011). Normal walking speed: A descriptive meta-analysis. Physioterapy, 97, 182-189.

Dobkin, B. H. (2005). Rehabilitation after stroke. New England Journal of Medicine, 352, 1677-1684.

Donnellan, C., Hevey, D., Hickey, A., \& O’Neill, D. (2012). Adaptation to stroke using a model of successful aging. Neuropsychology, Development, and Cognition Section B, Aging, neuropsychology and Cognition, 19, 530-547.

Duim, E., Lebrão, M. L., \& Antunes, J. L. F. (2017). Walking speed of older people and pedestrian crossing time. Journal of Transport \& Health, 5, 70-76.

Faria, C. D. C. M., Teixeira-Salmela, L. F., \& Gomes Neto, M., Rodrigues-de-Paula, F. (2012). Performance-based tests in subjects with stroke: Outcome scores, reliability and measurement errors. Clinical Rehabilitation, 26, 460-469.

Faria-Fortini, I., Basílio, M. L., Polese, J. C., Menezes, K. K. P., Faria, C. D. C. M., Scianni A. A., et al. (2017). Social participation of individuals with chronic stroke. Revista Terapia Ocupacional Universidade São Paulo, 28, 71-78. [article in Portuguese].

Faria-Fortini, I., Basílio, M. L., Scianni, A. A., Faria, C. D. C. M., \& Teixeira-Salmela, L. F. (2018). Perfomance and capacitybased measures of locomotion, compared to impairment-based measures, best predicted participation in inidividuals with hemiparesis due to stroke. Disability \& Rehabilition, 40, 17911798.

Flansbjer, U. -B., Downham, D., \& Lexell, J. (2006). Knee muscle strength, gait performance, and perceived participation after stroke. Archives of Physical Medicine and Rehabilitation, 87, 974-980.

Katan, M., \& Luft, A. (2018). Global burden of stroke. Seminars in Neurology, 38, 208-211.

Kawajiri, H., Mishima, H., Asano, S., Kono, Y., Hayashi, H., Niwa J., et al. (2019). Maximum walking speed at discharge could be a prognostic factor for vascular events in patients with mild stroke: A cohort study. Archives of Physical Medicine and Rehabilitation, 100, 230-238.

Khanittanuphong, P., \& Tipchatyotin, S. (2017). Correlation of the gait speed with the quality of life and the quality of life classified according to speed-based community ambulation in Thai stroke survivors. NeuroRehabilitation, 41, 135-141.

Law, M. (2002). Participation in the occupations of every life. American Journal of Occupational Therapy, 56, 640-649.

Lusardi, M. M. (2012). Is walking speed a vital sign? Absolutely! Topics in Geriatric Rehabilitation, 28, 67-76.

Mehrholz, J., Thomas, S., \& Elsner, B. (2017). Treadmill training and body weight support for walking after stroke. Cochrane Database Systematic Review, 8, CD002840. doi: 10.1002/14651858.CD002840

Middleton, A., Fritz, S. L., \& Lusardi, M. (2015). Walking speed: The functional vital sign. Journal of Aging and Physical Activity, 23, 314-322.

Munro, B. H. (2005). Statistical methods for health care research. 5th ed. Philadelphia: Lippincott Williams \& Wilkins.

Nascimento, L. R., Caetano, L. C., Freitas, D. C., Morais, T. M., Polese, J. C., \& Teixeira-Salmela, L. F. (2012). Different instructions during the ten-meter walking test determined significant increases in maximum gait speed in individuals with 
chronic hemiparesis. Brazilian Journal of Physical Therapy, $16,122-127$.

Noreau, L., Fougeyrollas, P., Vicent, C. (2002). The LIFE-H assessment of the quality of social participation. Technology and Disability, 14, 113-118.

Obembe, A. O., \& Eng, J. J. Rehabilitation interventions for improving social participation after stroke: A systematic review with meta-analysis. Neurohabilitation and Neural Repair, 30, 384-392.

Patterson, S. L., Forrester, L. W., Rodgers, M. M., Ryan, A. S., Ivey, F. M., Sorkin, J. D., et al. (2007). Determinants of walking function after stroke: Differences by deficit severity. Archives of Physical Medicine and Rehabilitation, 88, 115-119.

Perry, J., Garrett, M., Gronley, J. K., \& Mulroy, S. J. (1995). Classification of walking handicap in the stroke population. Stroke, 26, 982-989.

Pirker, W., \& Katzenschlager, R. (2017). Gait disorders in adults and the elderly: A clinical guide. Wiener klinische Wochenschrift, 129, 81-95.

Robinson, C. A., Shumway-Cook, A., Matsuda P. N., \& Ciol, M. A. (2011). Understanding physical factors associated with participation in community ambulation following stroke. Disability and Rehabilitation, 33, 1033-1042.

Rosa, M. C., Marques, A., Demain, S., \& Metcalf, C. D. (2015). Fast gait speed and self-perceived balance as valid predictors and discriminators of independent community walking at 6 months post-stroke - a preliminary study. Disability and Rehabilitation, 37, 129-134.

Rozon, J., \& Rochette, A. (2015). Changes in life habits affected by mild stroke and their association with depressive symptoms. Journal of Rehabilitation Medicine, 47, 495-501.

Schmid, A., Duncan, P., Studenski, S., Lai, S. M., Richards, L., Perera, S., et al. (2007). Improvements in speed-based gait classifications are meaningful. Stroke, 38, 2096-2100.
Sullivan, K. J., Tilson, J. K., Cen, S. Y., Rose, D. K., Hershberg, J., Correa, A., et al. (2011). Fugl Meyer Assessment of sensorimotor function after stroke: Standardized training procedure for clinical practice and clinical trials. Stroke, 42, 427-432.

Timmermans, C., Roerdink, M., van Ooijen, M. W., Meskers, C. G., Janssen, T. W., \& Beek, P. J. (2016). Walking adaptability therapy after stroke: Study protocol for a randomized controlled trial. Trials, 17, 425. doi: 10.1186/s13063-016-1527-6

van de Port, I. G., Kwakkel, G., \& Lindeman, E. (2008). Community ambulation in patients with chronic stroke: How is it related to gait speed? Journal of Rehabilitation Medicine, 40, 23-27.

Vanbrabant, L., Van De Schoot, R., \& Rosseel, Y. (2015). Constrained statistical inference: Sample size tables for ANOVA and regression. Frontiers in psychology, 5, 1565. doi: 10.3389/fpsyg.2014.01565

Vicent-Onabajo, G. O., Hamzat, T. K., \& Owolabi, M.O. (2015). Consistent determinants of health-related quality of life first 12 months after stroke: A prospective study in Nigeria. Topics in Stroke Rehabilitation, 22, 127-133.

Vicent-Onabajo, G. V., \& Blasu, C. (2016). Participation in leisure activities after stroke: A survey of community-residing stroke survivors in Nigeria. NeuroRehabilitation, 38, 45-52.

Wing, K., Lynskey, J. V., \& Bosch, P. R. (2012). Walking speed in stroke survivors: Considerations for clinical practice. Topics in Geriatric Rehabilitation, 28, 113-121.

Word Health Organization. International Classification of Functioning, Disability and Health. Geneva: World Health Organization; 2001. 